\title{
Testing of a Bipolar Solid-State Marx Generator for Berlin BESSY II Injection Kicker System
}

\author{
L. M. Redondo ${ }^{\circledR}$, Senior Member, IEEE, A. Kandratsyeu, T. Atkinson, and O. Dressler
}

\begin{abstract}
This article describes the preliminary results from the new bipolar solid-state Marx generator proposed for Berlin BESSY II injection system, which includes the following pulse specifications: (1) peak voltage of $\pm 8 \mathrm{kV}$, (2) peak current of $160 \mathrm{~A}$, (3) impedance of $50 \Omega$, (4) frequency $\leq 10 \mathrm{~Hz}$, (5) width of $350 \mathrm{~ns}$, (6) risetime $\leq 80 \mathrm{~ns}$, and (7) deviation from "Flat top" $\leq \pm 1 \%$. The generator is based on $\mathrm{SiC}$ metal-oxide-semiconductor field-effect transistors (MOSFETs) in order to allow fast risetime/falltime, where the charging of the main capacitors is from resistive paths. A generator with ten stages, using a dummy load that simulates a kicker magnet, is experimentally tested in order to study the overall performance, and results are presented and discussed.

Index Terms-High-speed electronics, particle accelerator magnets, power metal-oxide-semiconductor field-effect transistors (MOSFETS), pulse power systems, solid-state Marx generator, Thyratron replacement.
\end{abstract}

\section{INTRODUCTION}

$\mathbf{H}$ IGH-VOLTAGE pulsed generators, based on semiconductor switch technology, are being actively developed nowadays to replace established hard-tube-based generators, using Thyratron and pulse-forming networks/lines (PFNs/PFLs), in accelerator applications [1]-[5]. One of the most promising switch technologies is the silicon carbide (SiC) metal-oxide-semiconductor field-effect transistors (MOSFETs), where the high-speed commutation characteristics, together with low losses, make this type of devices very attractive. However, the still relatively low voltage and current capabilities of the semiconductors, in particular $\mathrm{SiC}$ MOSFETs, impose the use of stack techniques to achieve the needed voltage and current pulse amplitudes for accelerator applications; one technique that has been actively pursued is the Marx generator topology [6]-[8].

This article is related to testing a bipolar Marx generator topology developed for the Berlin BESSY II injection kicker system [9]-[11]. Traveling wave kicker magnets are applied for injection into and extraction from the BESSY II

Manuscript received February 22, 2021; revised March 31, 2021; accepted April 16, 2021. Date of publication May 5, 2021; date of current version June 10, 2021. The review of this article was arranged by Senior Editor R. P. Joshi. (Corresponding author: L. M. Redondo.)

L. M. Redondo is with the Pulsed Power Advanced Applications Group, Instituto Superior de Engenharia de Lisboa (GIAAPP/ISEL), 1959007 Lisbon, Portugal (e-mail: lmredondo@deea.isel.ipl.pt).

A. Kandratsyeu is with EnergyPulse Systems, Estrada do Paço do Lumiar, Pólo Tecnológico de Lisboa, 1600-546 Lisbon, Portugal (e-mail: oleg.kondratiev@energypulsesystems.com).

T. Atkinson and O. Dressler are with the Department Accelerator Operation and Technology/Injectors Group (BE-IA-AOT/INJ), Helmholtz-Zentrum Berlin, 14109 Berlin, Germany (e-mail: terry.atkinson@helmholtz-berlin.de; olaf.dressler@helmholtz-berlin.de).

Color versions of one or more figures in this article are available at https://doi.org/10.1109/TPS.2021.3075026.

Digital Object Identifier 10.1109/TPS.2021.3075026

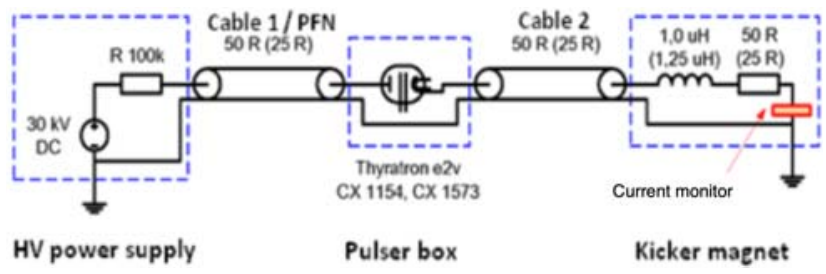

Fig. 1. Circuit topology of traveling wave kicker pulser systems for BESSY II booster.

booster synchrotron. The equipment is based on robust Thyratron switch technology and a rather simple circuit topology (Fig. 1). While the injection kicker system has a characteristic impedance of $50 \Omega$, the extraction kicker systems are designed for $25 \Omega$.

The characteristic of the circuit topology, in Fig. 1, is that the Thyratron is isolated from ground potential. A voltage pulse of half the PFN charging voltage is launched into cable 2 when the switch turns ON. This means that only half of the voltage is transferred to the load. For the duration of the pulse, the trigger electronics must withstand this half changing voltage as well [11].

The injection kicker magnet is energized over a $50-\Omega$ cable from kicker pulser box. The HV supply, the kicker pulser box, and the trigger and control electronics are situated outside the booster tunnel with distance to the magnets. This fact makes a semiconductor-based generator replacement feasible, since semiconductors are more susceptible to higher failure rates when exposed to ionizing radiation, as it is the case if generator device is installed inside an accelerator tunnel. In addition, maintenance is easier outside the tunnel. A filter circuit could be introduced as well at the end of the cable for risetime shaping [11].

The not perfectly matched kicker magnet will cause a reflection between the magnet and the pulse generator. In order to delay this reflection for after the pulse, cable 2 has a length of $80 \mathrm{~m}$.

The traveling wave kicker systems, as key components of the booster synchrotron, have a direct impact on the stable and uninterrupted top up mode operation of BESSY II synchrotron and storage ring. For the operation of BESSY II booster, the following is desired: (1) high availability and reliability of kicker systems during operation, (2) high average lifetime of the switches used, (3) best possible stability for suppressing timing jitter and drift, (4) high amplitude accuracy and simultaneously good flat-top of the current pulses, (5) small EMI, low sensitivity to external EMI radiation, and (6) steep falltime and risetime for turn OFF (injection) or turn ON (extraction kicker). 
However, various problems were detected on the pulser systems currently used, such as (1) damage of the insulation in the kicker pulser boxes by heating of the Thyratrons, (2) aging of the Thyratron causes timing drifts, (3) beating between the stable $10 \mathrm{~Hz}$ of the booster powering white circuits and $50-\mathrm{Hz}$ line frequency, (4) short life time of the Thyratrons in the applied circuit topology, assumingly damaged by sharp risetimes, and (5) for the top up mode operation, the primary sides of the devices are permanently on HV.

Hence, the foreseen solution for the discovered deficiencies could be the development of new pulser systems based on the advanced technology of solid-state switches. Solid-state Marx generators have become a mature technology nowadays, being a reliable solution in several industrial applications, including accelerator applications for Thyratron replacement.

The pulse specifications for injection kicker include: (1) voltage up to $8 \mathrm{kV}$, positive or negative, (2) peak current of $160 \mathrm{~A}$, (3) loop load impedance of $50 \Omega$, (4) repetition rate $\leq 10 \mathrm{~Hz}$, (5) width of $350 \mathrm{~ns}$, (6) risetime $\leq 80 \mathrm{~ns}$, and (7) deviation from "Flat top" $\leq \pm 1 \%$. The positive pulse current is required to power the kicker magnet for beam injection into the booster synchrotron. Both the polarities, positive and negative, are necessary if the kicker pulser device is used to drive a separate diagnostic kicker magnet as an exciter for beam studies.

Considering various stacked stages of a Marx generator, using semiconductor switches, several challenges become obvious, in order to fulfil the required specifications such as the synchronization of the semiconductor triggering, the jitter, and the fast risetime.

The presented article is dedicated to the development of a MOSFET based bipolar Marx proposed for Berlin BESSY II injection system, using a dummy load that simulates the Kicker magnet, for various operating conditions, in order to study its overall performance.

\section{Bipolar MARX Generator Topology}

\section{A. General Marx Bipolar Topology}

The simplified topology of a general bipolar solid-state generator, with $n$ stages, capable of delivering repetitive positive and/or negative high voltage output pulses to a load, $R_{0}$, using MOSFETs as ON-OFF switches, is presented Fig. 2, where $i \in\{1, \ldots, n\}$.

In this topology, the number of main capacitors $\mathrm{Cn}+1$ exceeds by one of the solid-state switch stages, $n$, where the first capacitor, $\mathrm{C} 1$, just contributes to the positive pulses and the last, $\mathrm{Cn}+1$, to the negative pulses, as described in detail elsewhere [12]. Also, each stage comprises diodes, Dai and Dbi and four switches, Sai, Sbi, Spi, and Sni.

In the circuit presented in Fig. 2, the operating modes are rather simple as the Ci capacitors are charged from the Udc PS when switches Sai and Sbi are ON. The positive pulse is applied when switch Spi is ON, and the negative pulse is applied when switch Sni is ON, resulting in an applied output voltage with an amplitude of approximately $v_{0}=$ $\pm n \mathrm{Udc}$, considering no losses. However, the consequence for this simplicity is that the Spi and Sni switches hold-off a

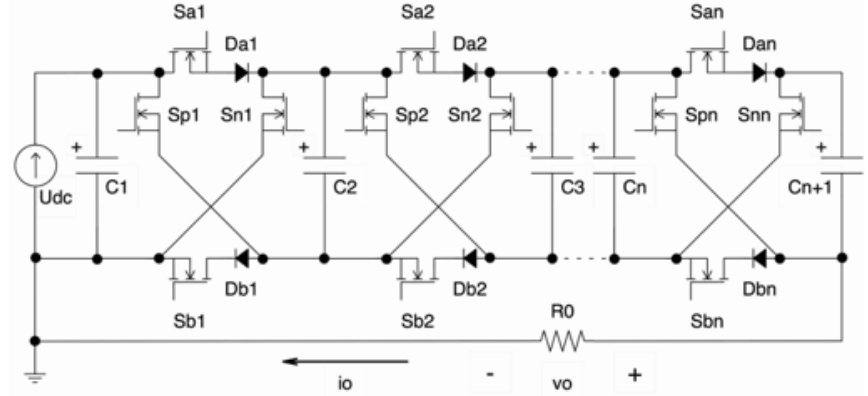

Fig. 2. General bipolar solid-state based Marx generator.

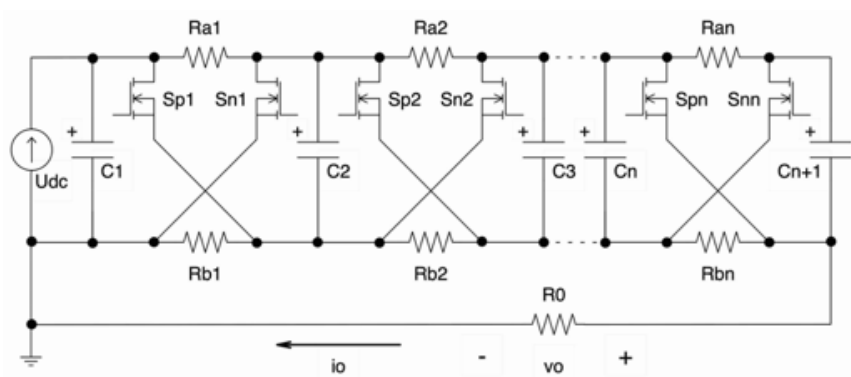

Fig. 3. Simplified bipolar solid-state based Marx generator.

voltage of $2 \mathrm{Udc}$, respectively, during the negative and positive pulses [12].

\section{B. Simplified Marx Bipolar Topology}

The circuit in Fig. 2 can be simplified, replacing the charging switches Sai and Sbi and diodes Dai and Dbi, respectively, by resistors Rai and Rbi, as shown in Fig. 3. This is possible as long as, during the charging mode, the capacitors $C_{i}$ voltage rise up to Udc, depending on: (1) the value of $\mathrm{R},(2)$ the value of the operating frequency, and (3) the number of stages.

The three main operating modes of the circuit in Fig. 3 are presented in Fig. 4, where Fig. 4(a) is the charging mode, Fig. 4(b) is the positive pulse mode, and Fig. 4(c) is the negative pulse mode.

For the given circuit topology during the charging mode, in Fig. 4(a), the equation that describes the time to charge the $n$th stage with a dc source is given approximately by [2] as

$$
T_{\text {chg }}=N^{2} R C, \text { where } 1 \leq n \leq N
$$

where $N$ is the stage number, $R=\mathrm{Rbi}=\mathrm{Rai}$, and $\mathrm{C}=$ Ci. For this application, the time to charge the last capacitor to Udc must be less than $1 /(10 \mathrm{~Hz})=100 \mathrm{~ms}$. The design of these resistances must consider, also, the self-discharging current paths of the $\mathrm{Ci}$ capacitors, through these resistors, during the pulse modes [i.e., $i$ (Rai) and $i(\mathrm{Rbi})]$, as seen in Fig. 4(b) and (c). Where, considering $R=\mathrm{Rbi}=$ Rai and $v_{\mathrm{Ci}}=\mathrm{Udc}$, these currents are approximately $\mathrm{Udc} / \mathrm{R}$. Hence, during the pulse, each switch (i.e., Spi and Sni) must conduct a current given, as

$$
i_{0}=v_{0} / R_{0}+2 \mathrm{Udc} / R .
$$

Finally, for safety reason a switch was additionally placed in parallel with capacitor $C 1$, so that in case of emergency, the Marx generator can be discharged rapidly (see Section III-B). 

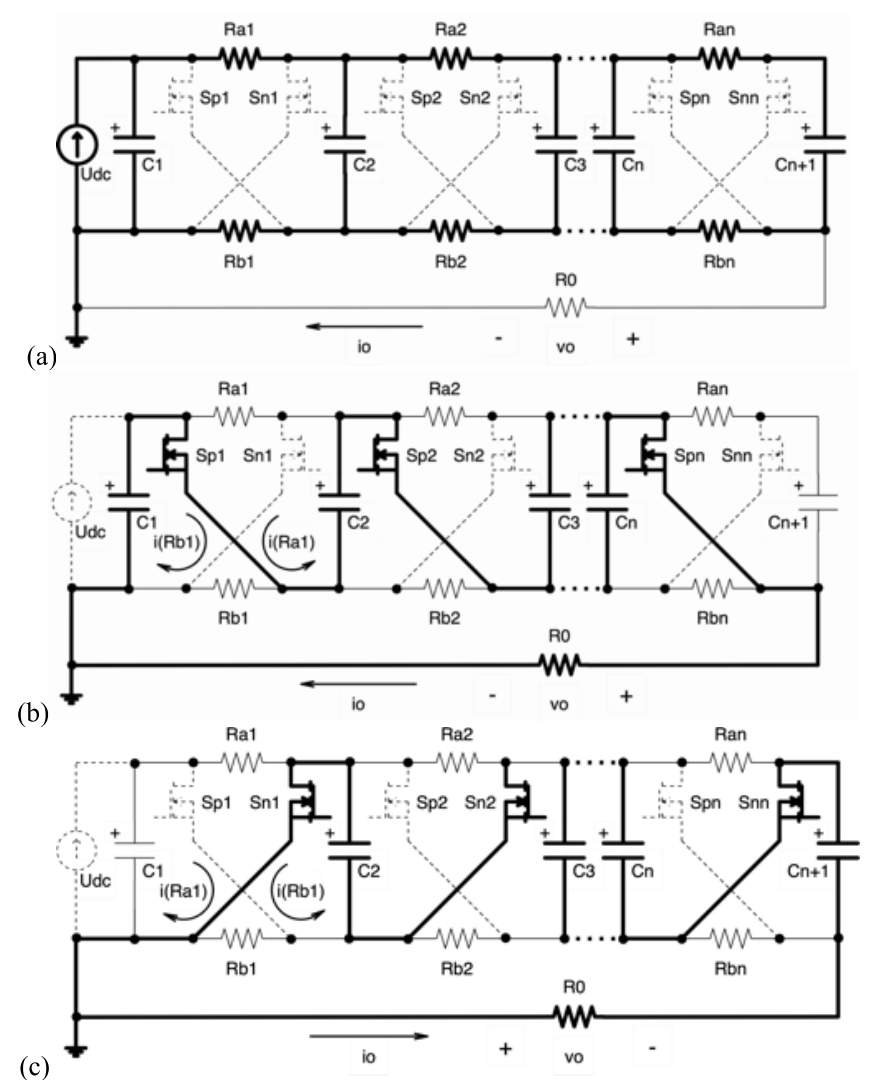

Fig. 4. Operating modes of Fig. 3 circuit. (a) Charging. (b) Positive pulse. (c) Negative pulse.

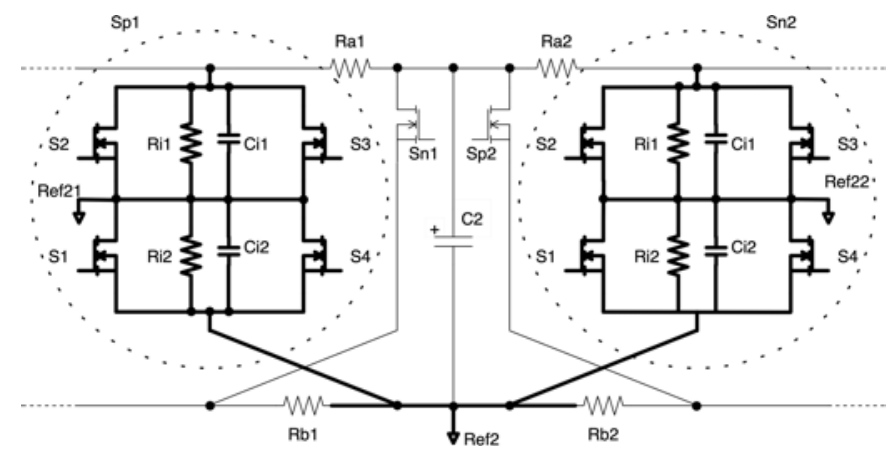

Fig. 5. Details of Sp1 and Sn2 switch assemblies, connected to the negative terminal of C2 capacitor, Ref2.

\section{Design Considerations for the Bipolar Marx Generator}

For the objective described in this application, the bipolar generator circuit in Fig. 3 was assembled with ten stages, 11 capacitors, for an Udc up to about $850 \mathrm{~V}$. For the Spi and Sni switches TO-263-7 C3M0065100J SiC Cree MOSFETs (i.e., 1000-V, 90-A pulsed current, and $65 \mathrm{~m} \Omega$ ) were chosen. Considering the pulse current and voltage hold-off, a series of two parallel devices was assembled as switches Spi and Sni, using four MOSFETs S1-S4, as shown in Fig. 5.

Considering Rai $=\mathrm{Rbi}=50 \Omega$, then the total switch Spi and Sni current is $194 \mathrm{~A}$, as (2), meaning that each MOSFET conduct a current of 97 A during pulse. Current sharing between the parallel MOSFETs is ensured by the trigger synchronization, equal track design and similar device characteristics. In order to improve the MOSFET series

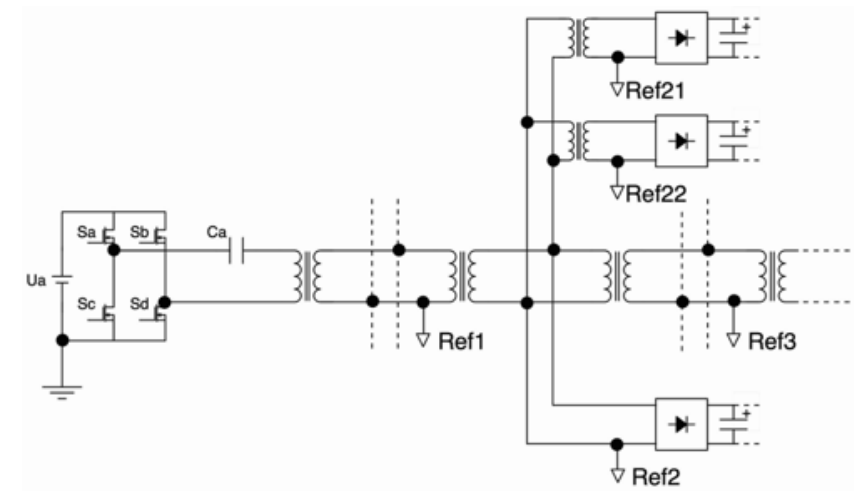

Fig. 6. Schematic simplified circuit for supplying power to each triggering stage, with details for the negative terminal of $\mathrm{C} 2$ capacitor, Ref2.

voltage sharing, a Rii Cii parallel branch was inserted, also, with $1 \mathrm{M} \Omega$ and $1 \mathrm{nF}$, as shown in Fig. 5.

The value $16 \mu \mathrm{F}$ was chosen for the $\mathrm{Ci}$ capacitance, comprising eight parallel 2- $\mu \mathrm{F}$ B32774D0205K0 EPCOS capacitors, giving 57.8-J stored energy in the Marx, and $96.8 \mathrm{~ms}$ to charge $\mathrm{C} 11$, as (1). Even after considering the increase of the pulse current, by the self-discharge capacitor's current iRai and iRbi, the estimated pulse voltage droop is less than $40 \mathrm{~V}$, lower than the $\pm 80-\mathrm{V}$ limit for the pulse flat top.

The pulse trigger signal is sent by fiber optics to the MOSFET drivers, where optical receiver HFBR-2521Z, optical transmitter HFBR-1521Z, and optical cable HFBR-RUS100Z, were used.

The signals from the fiber optics need to be amplified to fire the switches. Hence, in order to supply the power to all the switch drivers in the stages, a string of toroidal transformer was implemented, which is fed by a $100-\mathrm{kHz}$ inverter, as shown in Fig. 6.

As seen in Fig. 6, Ref1 is associated with the negative terminal of $\mathrm{C} 1$, Ref2 is associated with the negative terminal of $\mathrm{C} 2$ (i.e., switches $\mathrm{S} 1$ and $\mathrm{S} 4$ from $\mathrm{Sp} 1$ and switches $\mathrm{S} 1$ and $\mathrm{S} 4$ from Sn2), shown in Fig. 5, and so on. In addition, it is shown, in Fig. 5, the supply of power for the electronics located in Ref21 (i.e., switches S2 and S3 from Sp1) and Ref22 (i.e., switches S2 and S3 from Sn2), as seen in Fig. 5. In summary, there is a primary transformer string for each Marx stage for supplying power to the electronics in Refi, and from that two more additional transformers are used to power different voltage references, Refji.

\section{Results AND ANALYSis}

The implemented Marx generator is shown in Fig. 7, which is enclosed in a grounded 19" stainless steel box, without any ventilation apertures to minimize electromagnetic interference and the input of dust from outside as well.

In Fig. 7, the implemented Marx generator can be divided in two parts, the left and right, respectively, for the positive and negative pulse circuits, which are triggered by side position optic fibers. In between the positive and negative stacks, there are toroidal transformers that supply power to the triggering stages, as described in Fig. 6.

An experimental setup was assembled to test the generator, using an equivalent dummy load to the Kicker magnet, shown 


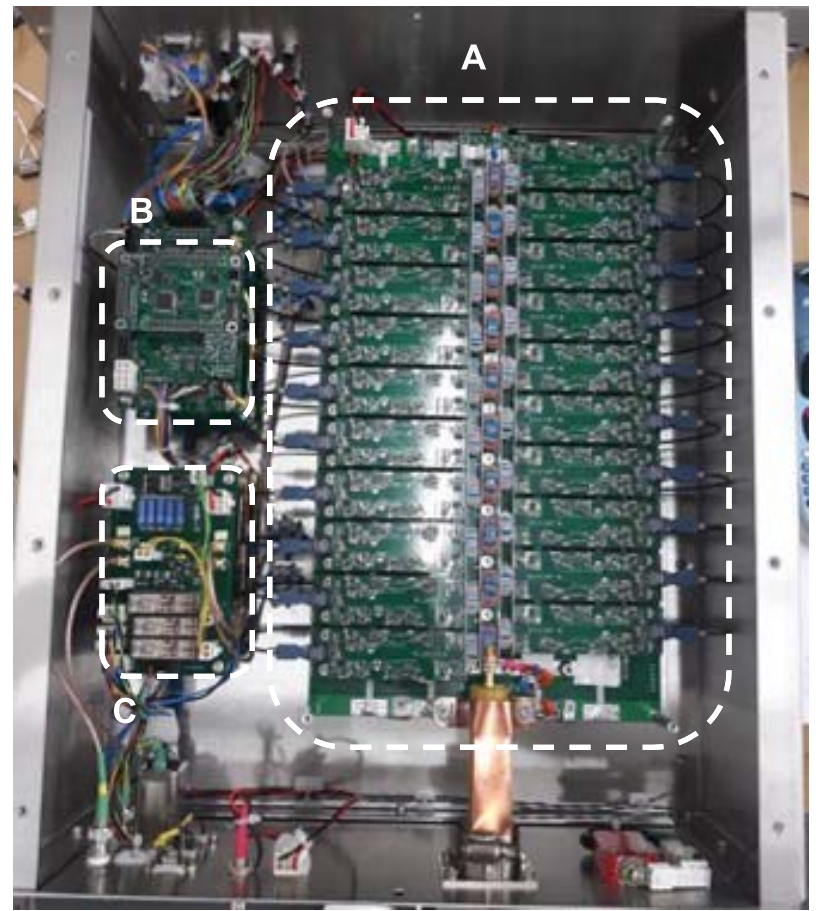

Fig. 7. Top view picture of the 19-inch rack of the generator. A: Marx generator, B: control $\mu \mathrm{C}$ board, and $\mathrm{C}$ : auxiliary power supplies and safety interlocks.

(a)

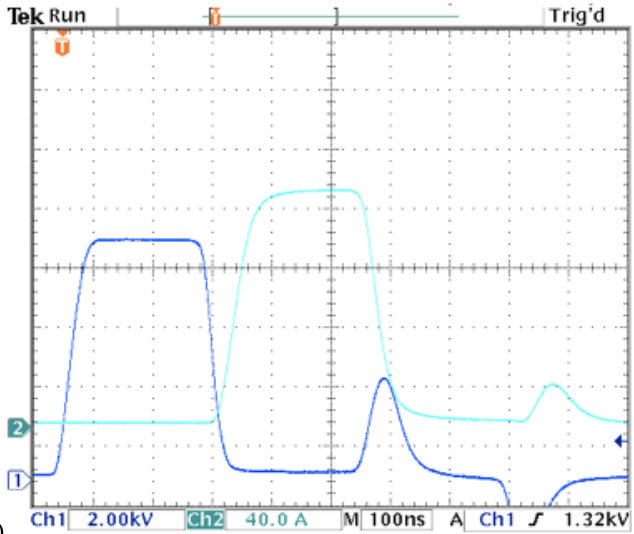

(b)

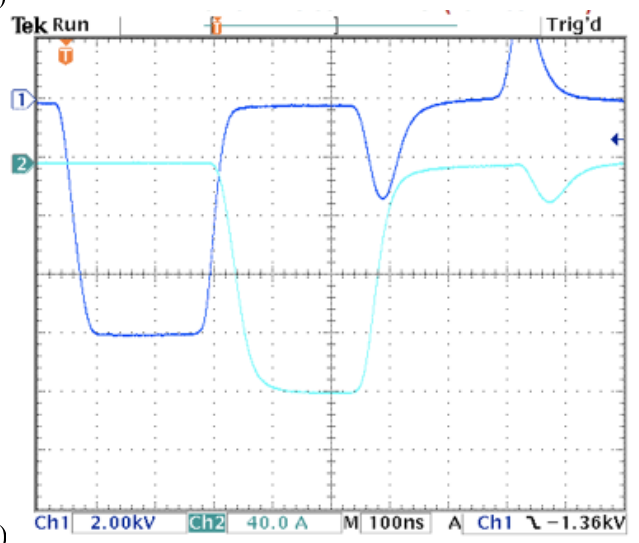

Fig. 8. Output Marx generator voltage (blue) and load current (cyan). (a) Positive pulse. b) Negative pulse. Voltage $2 \mathrm{kV} / \mathrm{div}$, current $40 \mathrm{~A} / \mathrm{div}$, and $100 \mathrm{~ns} / \mathrm{div}$.

in Fig. 1, comprising a 50- $\Omega$ noninductive resistor in series with a piece of copper wound to give $1.2-\mu \mathrm{H}$ load, connected to the generator by HV RG 218 50-m cable. Unless described

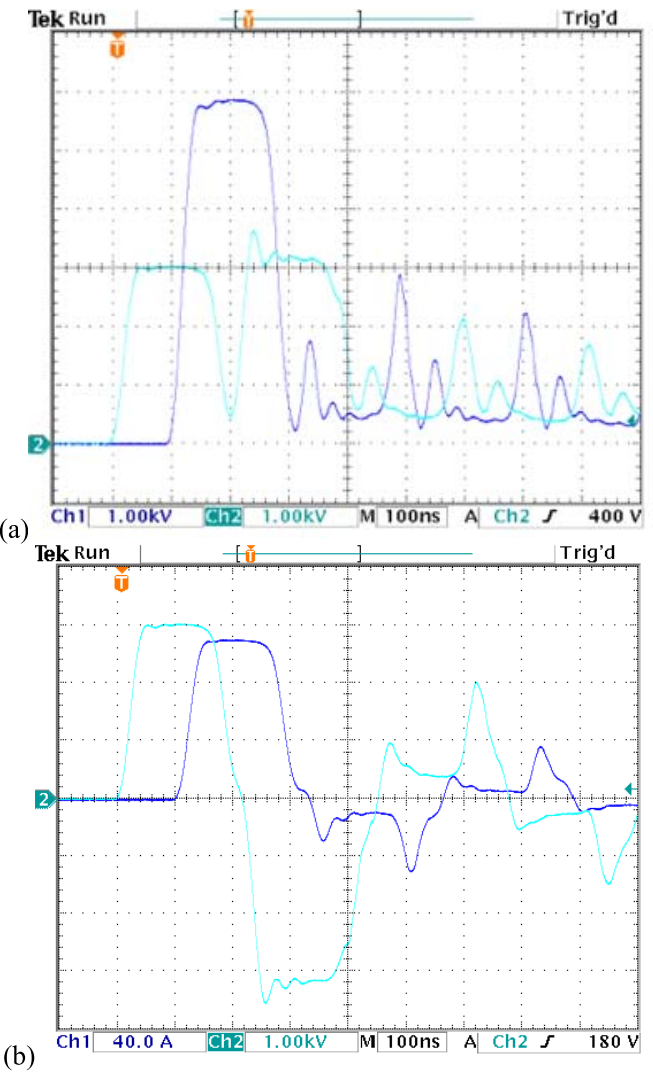

Fig. 9. (a) Open-load condition, output Marx generator voltage (cyan) and open-end cable voltage (blue). (b) Load short-circuit condition, output generator voltage (cyan) and short-circuit load current (blue): $1 \mathrm{kV} / \mathrm{div}$, current $40 \mathrm{~A} / \mathrm{div}$, and $100 \mathrm{~ns} / \mathrm{div}$.

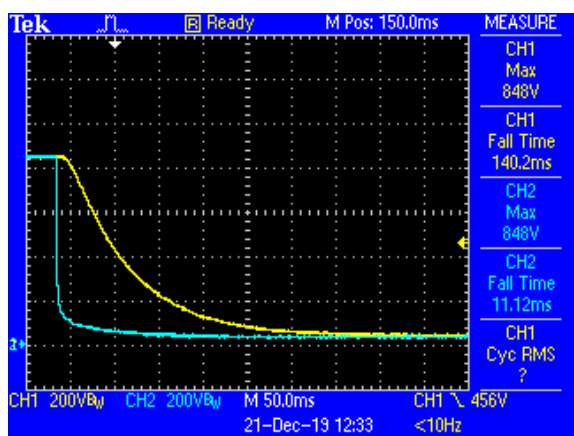

Fig. 10. Discharge of $\mathrm{C} 1$ (cyan) and $\mathrm{C} 11$ (yellow) capacitors, with full charged Marx, during an emergency: $50 \mathrm{~ms} /$ div and $200 \mathrm{~V} /$ div.

otherwise, voltage waveforms were recorded with a Tektronix TPS2024B 200-MHz 2-GS/s oscilloscope, using PMK PHV1000 100:1 400-MHz 50-M $\Omega / / 7.5-p F$ high voltage probe. The current measurements were recorded using a Bergoz CT-E0.1-B current transformer.

\section{A. Positive and Negative Pulse Operation}

Fig. 8 shows the output Marx generator $8-\mathrm{kV}$ positive and negative, 350-ns width, voltage pulses and 160-A load currents, considering an $850-\mathrm{V}$ external input voltage.

It can be seen, from Fig. 8, that the voltage reflection at about $500 \mathrm{~ns}$ is compatible with the length of the cable used for testing, i.e., $50 \mathrm{~m}$, and the $5 \mathrm{~ns}$ per meter propagation velocity. Also, it is seen in Fig. 8, the load current shifted by $250 \mathrm{~ns}$, from the Marx pulse voltage output. In addition, 
the risetime and falltime for the current pulses are about $57 \mathrm{~ns}$, between $10 \%$ and $90 \%$.

\section{B. Open-Circuit and Short-Circuit Operation}

Fig. 9 shows the operation of the Marx generator for two fault conditions: (1) load not connected, cable end open-circuit and (2) load short-circuit, cable end short-circuit. These results were taken for a $20-\mathrm{m}$ cable length connection, considering a 300-V external input voltage.

It can be seen, from Fig. 9(a), for the open-circuit condition (i.e., transmission coefficient of 2 and reflection coefficient of 1), the voltage at the open-cable end with twice the output Marx voltage and the output Marx voltage with a reflection after $200 \mathrm{~ns}$, corresponding to the 20-m cable. In addition, it can be seen, from Fig. 9(b), for the short-circuit condition (i.e., transmission coefficient of 0 and reflection coefficient of $-1)$, the short-circuit current at the load shifted $100 \mathrm{~ns}$ from the output Marx voltage, and negative output Marx voltage reflection after $200 \mathrm{~ns}$, corresponding to the 20-m cable.

Finally, Fig. 10 shows the discharge of the $\mathrm{C} 1$ and $\mathrm{C} 11$ capacitors, during an emergency situation (e.g., vacuum fault), where the switch in parallel with $\mathrm{C} 1$ capacitor is turned $\mathrm{ON}$. As seen, the time constant of the discharge increases from the first $\mathrm{C} 1$ to the last $\mathrm{C} 11$, nevertheless the last capacitor achieves a voltage of $50 \mathrm{~V}$ in less than $300 \mathrm{~ms}$, within the safety regulations.

\section{CONCLUSION}

A bipolar Marx generator, based on SiC MOSFETs, was demonstrated to deliver bipolar pulses to a dummy load, equivalent of the Berlin BESSY II injection kicker, with the following pulse specifications: (1) peak voltage of $\pm 8 \mathrm{kV}$, (2) peak current of $160 \mathrm{~A}$, (3) impedance of $50 \Omega$, (4) frequency $\leq 10 \mathrm{~Hz}$, (5) width of $350 \mathrm{~ns}$, (6) risetime $\leq 80 \mathrm{~ns}$, and (7) deviation from "Flat top" $\leq \pm 1 \%$. In addition, the circuit path to charge the Marx capacitors is based on resistors which allow both for the charge of the capacitors within $100 \mathrm{~ms}$ and the fast discharge of the Marx energy in less than $300 \mathrm{~ms}$ in case of an emergency.

Plans for future include a more detailed analysis of generator operation using the real Kicker injection system.

\section{REFERENCES}

[1] I. Roth, M. Gaudreau, and M. Kempkes, "Thyratron replacement," in Proc. IEEE Int. Vac. Electron. Conf. (IVEC), Monterey, CA, USA, Apr. 2016, pp. 1-2, doi: 10.1109/IVEC.2016.7561837.

[2] W. Liu, J. Powe, M. Cond, W. Ga, and H. Sanders, "AWA RF mdulator upgrade using solid state thyratron replacement," in Proc. IEEE Pulsed Power Conf. (PPC), Austin, TX, USA, May 2015, pp. 1-4, doi: 10.1109/PPC.2015.7296916.

[3] H. D. Sanders, S. C. Glidden, and C. T. Dunham, "Solid state switches for high frequency operation as thyratron replacements," in Proc. 19th IEEE Pulsed Power Conf. (PPC), San Francisco, CA, USA, Jun. 2013, pp. 1-4, doi: 10.1109/PPC.2013.6627483.

[4] A. Welleman, W. Fleischmann, and W. Kaesler, "Solid state on-off switches using IGCT technology," in Proc. 16th IEEE Int. Pulsed Power Conf., Albuquerque, NM, USA, Jun. 2007, pp. 1025-1028.

[5] R. L. Cassel, "An all solid state pulsed Marx type modulator for magnetrons and klystrons," in Proc. IEEE Pulsed Power Conf., Monterey, CA, USA, Jun. 2005, pp. 836-838, doi: 10.1109/PPC.2005.300791.

[6] L. M. Redondo, A. Kandratsyeu, and M. J. Barnes, "Marx generator prototype for kicker magnets based on SiC MOSFETs," IEEE Trans. Plasma Sci., vol. 46, no. 10, pp. 3334-3339, Oct. 2018, doi: 10.1109/TPS.2018.2808194
[7] R. Risch and J. Biela, "Nanosecond switching of ohmic loads using SiC MOSFETs in ultra-low inductive PCB-packages," in Proc. 21st Eur. Conf. Power Electron. Appl. (EPE ECCE Europe), Genova, Italy, Sep. 2019, p. 10, doi: 10.23919/EPE.2019.8914901.

[8] L. M. Redondo and J. F. Silva, "Repetitive high-voltage solidstate Marx modulator design for various load conditions," IEEE Trans. Plasma Sci., vol. 37, no. 8, pp. 1632-1637, Aug. 2009, doi: 10.1109/TPS.2009.2023221.

[9] O. Dressler and J. Feikes, "Operational experiences with the BESSY II injection system," in Proc. Part. Accel. Conf., New York, NY, USA, 1999 , pp. $1279-1281$.

[10] O. Dressler, V. Pickert, and C. Rediess, "IGBT driver circuit in inductive adder adder technology for pulsed power applications," in Proc. PCIM Eur., Int. Exhib. Conf. Power Electron., Intell. Motion, Power Qual., 2008, pp. 1-5, doi: 10.1109/PAC.1999.795521.

[11] O. Dressler, J. Feikes, and J. Kolbe, "A diagnostic kicker system as a versatile tool for storage ring characterisations," in Proc. 10th Eur. Part. Accel. Conf. (EPAC), London, U.K., 2006, pp. 974-976.

[12] H. Canacsinh, L. M. Redondo, and J. F. Silva, "Marx-type solidstate bipolar modulator topologies: Performance comparison," IEEE Trans. Plasma Sci., vol. 40, no. 10, pp. 2603-2610, Oct. 2012, doi: 10.1109/TPS.2012.2190944.

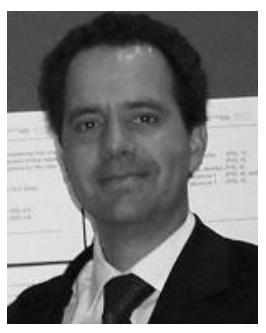

L. M. Redondo (Senior Member, IEEE) received the B.Sc. and Dipl.Eng. degrees in electrical engineering from the ISEL-IPL, Lisbon, Portugal, in 1990 and 1992, respectively, the M.Sc. degree in nuclear physics from FCUL, Lisbon, in 1996, and the Ph.D. degree in electrical and computer engineering from IST-UTL, Lisbon, in 2004.

$\mathrm{He}$ is currently a Coordinator Professor at ISEL, teaching power electronics and digital systems. His research interest includes pulsed power systems for industrial applications.

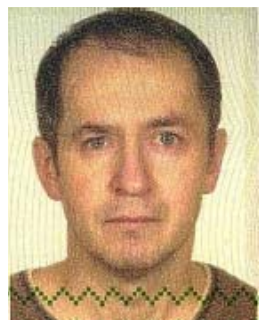

A. Kandratsyeu graduated in physics from Belarusian State University, Minsk, Belarus, in 1994, and received the master's degree from Belarusian State University in 1997.

From 1992 to 1999, he worked as a Researcher at the Institute for Nuclear Problem, Minsk. From 1997 to 1998, he worked in the Gie $\beta$ en Physics Institute, Germany. From 1999 to 2006, he worked as an Electronic Research and Development Engineer with Linline Company, Minsk, and from 2006 to 2014, he worked as an Electronic Research and Development Engineer with Oem-Tech Company, Minsk. In 2015, he joined EnergyPulse Systems, Lisbon, Portugal, developing solid-state pulsed power electronics.

T. Atkinson received the B.Sc. degree in physics from University College London, London, U.K., in 2003, and the Ph.D. degree in physics from Humboldt-Universität zu Berlin, Berlin, Germany, in 2015.

$\mathrm{He}$ works as a Scientist with the Institute of Accelerator Physics, Helmholtz-Zentrum Berlin (HZB), Berlin, where he is the Head of the Injector Group and a Special Representative at the metrology light source (MLS).

O. Dressler received the Dipl.-Ing. degree in electrical power engineering from Hochschule für Technik und Wirtschaft, Berlin, Germany, in 1994, the Dipl.-Wirtsch.-Ing. degree in industrial engineering and management from Technische Hochschule Wildau, Wildau, Germany, in 1997, and the M.Sc. degree in electrical power from Newcastle University, Newcastle upon Tyne, U.K., in 2007.

He works in the Accelerator Operation, Development and Technology Department, Helmholtz-Zentrum Berlin, Berlin, in the field of pulse power supplies and pulsed magnets as a Research and Development Engineer. 